\title{
Personalized approach to growth hormone replacement in adults
}

${ }^{1}$ Amsterdam UMC, Vrije Universiteit Amsterdam, Department of Internal Medicine, Sub-section of Endocrinology, Amsterdam, Netherlands ${ }^{2}$ Department of Internal Medicine and Clinical Nutrition, Institute of Medicine at Sahlgrenska Academy, University of Gothenburg, Göteborg, Sweden, and Department of Endocrinology, Sahlgrenska University Hospital, Göteborg, Sweden

Correspondence to: Daniel S. Olsson Department of Endocrinology, Institute of Medicine, Sahlgrenska Academy, University of Gothenburg and Sahlgrenska University Hospital, Gröna Stråket 8, 41345

Gothenburg, Sweden daniel.olsson@gu.se

Received on Sept/13/2019 Accepted on Oct/4/2019

DOI: 10.20945/2359-3997000000189

\author{
Christa C. van Bunderen' \\ http://orcid.org/0000-0003-0006-7726 \\ Camilla Glad ${ }^{2}$ \\ http://orcid.org/0000-0003-4826-215X \\ Gudmundur Johannsson ${ }^{2}$ \\ http://orcid.org//0000-0003-3484-8440 \\ Daniel S. Olsson² \\ http://orcid.org/0000-0002-9734-0786
}

\begin{abstract}
Growth hormone (GH) deficiency (GHD) in adults is well-characterized and includes abnormal body composition, reduced bone mass, an adverse cardiovascular risk profile, and impaired quality of life. In the early 1990s, it was also shown that patients with hypopituitarism without GH replacement therapy (GHRT) had excess mortality. Today, GHRT has been shown to decrease or reverse the negative effects of GHD. In addition, recent papers have shown that mortality and morbidity are approaching normal in hypopituitary patients with GHD who receive modern endocrine therapy including GHRT. Since the first dose-finding studies, it has been clear that efficacy and side effects differ substantially between patients. Many factors have been suggested as affecting responsiveness, such as sex, age, age at GHD onset, adherence, and GH receptor polymorphisms, with sex and sex steroid replacement having the greatest impact. Therefore, the individual tailoring of $\mathrm{GH}$ dose is of great importance to achieve sufficient efficacy without side effects. One group that stands out is women receiving oral estrogen replacement, who needs the highest dose. Serum insulin-like growth factor-1 (IGF-1) is still the most used biochemical biomarker for GH dose titration, although the best serum IGF-1 target is still debated. Patients with GHD due to acromegaly, Cushing's disease, or craniopharyngioma experience similar effects from GHRT as others. Arch Endocrinol Metab. 2019;63(6):592-600
\end{abstract}

Keywords

Growth hormone; growth hormone replacement therapy; individualized medicine; tailoring of treatment

\section{INTRODUCTION}

$\mathrm{G}$ rowth hormone $(\mathrm{GH})$ deficiency (GHD) has I been a well-known clinical entity for a long time in children. To mitigate decreased linear growth in children, GH replacement therapy (GHRT) has been used since the late 1950s (1). Before 1985, when recombinant GH was approved in the US, the limited supply of pituitary-derived GH hindered research into its use in adults with GHD. Although a few early reports on the effects of GHRT in hypopituitary adults had already been published in the 1960s (2) and hypotheses had been made on the impact that GH might have in adults based on clinical studies in hypopituitarism (3), it was not until the availability of recombinant human $\mathrm{GH}$ that the research field of adult GHD was established.

Today, the consequences of GHD in adults are well defined and well described $(4,5)$. GHD in adults is most commonly caused by a pituitary or peripituitary tumor or its treatments. The main features of adult GHD include abnormal body composition, reduced muscle strength and exercise capacity, reduced bone mass, an adverse cardiovascular risk profile, and impaired quality of life. The abnormal body composition includes increased fat mass with abdominal distribution, and reduced muscle mass and extracellular water content. GHD is also associated with an abnormal plasma lipid profile. In addition, patients with GHD and hypopituitarism have been shown to have excess cardiovascular morbidity and mortality $(6,7)$.

Since the first two double-blind, placebo-controlled studies of GHRT in adults were reported in 1989, daily GHRT has been shown to reverse or ameliorate many of the symptoms associated with adult $\operatorname{GHD}(8,9)$. A metaanalysis of randomized, blinded, placebo-controlled trials showed that long-term GHRT has beneficial effects on muscle and fat mass, lipid profile, and diastolic blood pressure (10). Long-term GHRT has also been shown to increase bone mass and to improve quality of life, especially energy level and emotional reaction $(11,12)$. Furthermore, recent papers have shown that morbidity 
and mortality are close to normal in hypopituitary patients with GHD receiving modern replacement therapy, including GHRT and if needed personalized substitution of other pituitary axes $(13,14)$.

The aim of this review is to describe the individual variability in response to GHRT and, therefore, the importance of individualization of the treatment.

\section{INDIVIDUAL RESPONSE TO GHRT}

The first studies reporting on the efficacy and safety of GHRT in adults used a weight-based dose regimen which was basically copied from pediatric practice $(8,9,15)$. Side effects related to fluid retention induced by $\mathrm{GH}$ and the increased serum insulin-like growth factor-1 (IGF-1) were common. It soon became clear that older patients and those with higher body weight had a higher frequency of side effects (16), suggesting that an individualized approach was needed in order to reduce the prevalence of side effects and, at the same time, obtain similar efficacy (17-19). This was the start of the use of the dose-titration regimen which is today recommended by clinical guidelines $(20,21)$.

\section{Sex differences}

Observations were made in some of the early studies that the response to GHRT differed markedly among patients (17). The most obvious difference was that observed between the sexes, with men showing a more marked effect on body composition with a higher increase in lean body mass and extracellular water, and larger reduction in fat mass in response to GHRT $(22,23)$. Men also showed a more marked increase in serum IGF-1 in response to GHRT than women (17). This difference has been explained by the different interactions between $\mathrm{GH}$ and testosterone and estrogen, respectively. Testosterone augments the effects of $\mathrm{GH}$ through increasing muscle mass and extracellular water volume (24). Estrogen, on the other hand, may increase fat mass and reduce the serum IGF-1 response to GH. This effect of estrogen is dependent on the route of administration, as oral administration exposes the liver to supraphysiological estrogen doses in order to achieve physiological systemic exposure of estrogen due to first-pass hepatic metabolism (25). Oral estrogen, but not transdermal estrogen, therefore attenuates the increase in serum IGF- 1 concentration in response to $\mathrm{GH}$ and reduces lipid oxidation $(25,26)$. These effects help explain the sex differences seen in body composition in response to GHRT.

\section{Effect of age at GHD onset}

In some of the earlier studies on adult GHD patients, it became clear that the outcome of therapy differed depending on the timing of GHD onset, i.e. childhoodonset or adult-onset of GHD. Childhood-onset patients had more severe consequences in terms of changes in body composition (increased body fat, decreased lean body mass and decreased bone mass) (27), whereas their selfperceived quality of life was better than among adult-onset patients (28). The improvement in quality of life was less pronounced among those with childhood-onset disease (28), whereas the initial response in body composition was more marked (27). In a prospective 5-year followup study comparing adult-onset and childhood-onset GHD, which was well matched for age, sex, and degree of hypopituitarism, the long-term effects on body composition, bone mineral density, and muscle strength were similar, although the initial response was more marked in patients with childhood-onset disease (27). A confounder in these comparisons is that childhood-onset patients usually have a longer duration of GHD.

Whether age per se has an impact on the response to GHRT is unclear. During logistic regression analysis in a prospective single-center study, age was not found to be a significant predictor of response in terms of serum IGF-1 and body composition (29). Another large postmarketing database analysis showed that older patients responded to GHRT similarly to younger patients in terms of waist circumference, blood pressure, and lipids (30). Taken together, these data suggest that age per se is not a major predictor of the response to GHRT among adults.

\section{Pharmacogenetics}

While sex and age at onset of GHD explain some of the variability in the responsiveness to GHRT, other factors such as individual genotype may be of additional importance. To date, by far the most intensively studied genetic variant in this respect has been the $\mathrm{GH}$ receptor exon 3-deleted/full-length polymorphism. At a genetic level, each individual carries either two copies of the full-length receptor, two copies of the exon 3-deleted receptor (d3-receptor), or one of each (heterozygote). It was initially shown in a pediatric study that patients carrying the $\mathrm{d} 3$-receptor had a better growth response 
to GHRT than those with the full-length receptor (31). Since then, several studies in both children and adults have been performed in an attempt to further investigate the impact of the $\mathrm{GH}$ receptor isoforms on clinical response to GHRT and their findings have been detailed in a recent review (32). In summary, trials with a duration longer than 6 months showed that patients carrying the $\mathrm{d} 3$-receptor isoform had a marginally larger serum IGF-1 response, i.e. lower GH dose achieved the same IGF-1 response and, in some studies, a more favorable response in plasma lipids. On the other hand, one of the largest studies investigating the very rapid serum IGF-1 response after only a week of treatment showed a better serum IGF-1 response, after elimination of confounders (e.g. dose titration, adherence), in patients who were homozygous for the full-length receptor (33). Other studies, however, did not show any impact of GH receptor polymorphism on treatment response (32).

GH has various effects on humans, both directly and indirectly through IGF-1. For example, GH has important effects on hepatic lipoprotein metabolism that are mainly mediated through the $\mathrm{GH}$ receptor in the liver, and GH and IGF-1 increase extracellular water by affecting the renal tubules and through other mechanisms. Genotypes related to the functionality of these systems may therefore affect the responsiveness to GHRT. This concept has been explored in two different trials. In 318 adult patients with hypothalamic-pituitary disorder, the response to l-year of GHRT was studied in terms of lipid metabolism (34). Serum total cholesterol and low-density lipoprotein-cholesterol concentrations decreased, and serum high-density lipoproteincholesterol concentration increased. Among 20 preselected single-nucleotide polymorphisms (SNPs), two SNPs were found to be associated with the response to GHRT. The APOB SNP rs676210 GG genotype was associated with larger reductions in total cholesterol and low-density lipoprotein-cholesterol, and the PPARG SNP rs10865710 CC genotype with greater reduction in total cholesterol. In another study, the association between 19 pre-selected SNPs in genes related to renal tubular function and the extracellular water response after 1-year of GHRT were investigated (35). None of the studied SNPs had a significant impact during GHRT.

In summary, one particular polymorphism in the $\mathrm{GH}$ receptor gene has been associated with treatment response in some studies. The association is, however, weak and of little clinical significance when trying to identify those patients that would benefit the most from GHRT. Using genotype related to the end-points of interest for GHRT has also been able to show some associations, in particular in relation to lipid metabolism, but again the effect size of these associations is too small to be of clinical relevance, although they indicate a functional relationship.

\section{ADHERENCE}

For all long-term treatments, adherence is one of the factors that determines treatment success together with patient characteristics, therapy area challenges, treatment access, and healthcare provision (36). Individual responsiveness is therefore very likely influenced by adherence. Very few studies have examined the adherence of adult patients receiving longterm GHRT. One study examined adherence in 179 adult patients receiving GHRT assessed by calculating the percentage of available prescription data compared to recommended $\mathrm{GH}$ dosages over a mean follow-up period of approximately 7 years (37). Adherence during the first year was $85 \%$ and then gradually decreased, with the largest decline during the first 2 years. Young age and childhood onset of GHD were associated with low adherence, but not with the underlying diagnosis and the degree of hypopituitarism. In addition, no association was seen between change in serum IGF-1 concentration and adherence, suggesting that serum IGF-1 is not a reliable marker to assess individual adherence. Another study showed that approximately $35 \%$ of adult patients have poor adherence and were also skeptical of GHRT. This study also showed that younger age and childhood onset of GHD were associated with the poorest adherence (38).

Adherence is likely to be an important factor for individual responsiveness, although this has not been extensively studied. Factors that can be modified, based on pediatric studies, to improve adherence are lack of knowledge and understanding of the condition and its treatment, discomfort and pain associated with injections, and the quality of the healthcare professional-patient relationship (39).

\section{INDIVIDUAL TAILORING OF MANAGEMENT}

\section{Dose titration}

The weight- and body surface area-based dosing regimens of GHRT that were initially used were 
associated with adverse events (arthralgia and peripheral edema), especially in older, heavier, and female patients (16). Tailored dose-titration strategies with lower starting doses are therefore now recommended (19-21) (Table 1). Total IGF-1 is still recognized as the most useful biochemical biomarker for $\mathrm{GH}$ dose titration in adults (40). Alongside individualized dosing, current clinical guidelines state that the goals of treatment should be an appropriate clinical response, avoidance of side effects, and serum IGF-1 value within the ageadjusted reference range $(20,21)$. In clinical practice, it is still unclear how to dose GHRT and how to choose the appropriate target level for serum IGF-1 (within the age-adjusted reference ranges) in adults with GHD. Dose comparison studies have been conducted on the effect of low and high GH doses in relation to GHD at baseline $(41,42)$. A beneficial effect of GHRT was demonstrated in both treatment arms with no significant difference between the groups. Serum IGFl was never used as a treatment target but, indirectly, no correlations were found between several outcome measures and serum IGF-1 level. A recent open-label, randomized clinical trial compared low-normal and high-normal IGF-1 target levels on various clinical endpoints during GHRT in adult GHD $(43,44)$ (Table 1). Increasing the GH dose in order to achieve IGF- 1 levels between 1 and 2 standard deviation score (SDS) (adjusted for age and sex) improved waist circumference, microvascular function, and patient wellbeing. However, impaired effects on high-density lipoprotein-cholesterol in men, and insulin resistance and patient-reported myalgia in men and women were also seen with increasing the $\mathrm{GH}$ dose. In addition, when investigating cognitive function and mood in women, the adjustment of the $\mathrm{GH}$ dose seemed to have a narrow window. An increased dose appeared to impair prefrontal cognitive functioning, while a low dose resulted in decreased vigor. An IGF-1 target level between -1 and I SDS seems advisable; however, more scientific evidence is still warranted before implementation of this as a recommendation into current clinical practice. Gender, estrogen status, and age should be considered during dose titration due to the variability in response to GHRT. Furthermore, in certain special situations, an individualized choice of dose has to be made.

\section{Sex and age}

Women are less responsive to $\mathrm{GH}$, in particular those who are taking oral estrogens $(25,26)$. Therefore, women have been shown to need a higher starting dose and need higher $\mathrm{GH}$ doses during long-term treatment to achieve the same IGF- 1 target and clinical effect $(17,20,21,45)$. This difference results in women being more likely to be undertreated.

In healthy subjects, IGF- 1 declines with increasing age. Therefore, age should also be taken into account when choosing an appropriate IGF-1 target level (46). Age-adjusted reference values should be used to specify the target IGF-1 level. Initiating GHRT in elderly patients diagnosed with GHD is still debated. A systematic review by Kokshoorn and colleagues demonstrated clear improvements in lipid levels and quality of life in patients older than 60 years, but not in several other parameters (47). GHRT has similar

Table 1. Prospective studies investigating dose titration of GHRT

\begin{tabular}{|c|c|c|c|c|c|c|}
\hline Authors & Year & $\begin{array}{l}\text { No. of } \\
\text { patients }\end{array}$ & $\begin{array}{l}\text { Dose titration } \\
\text { IGF-1 target level }\end{array}$ & Comparator & $\begin{array}{l}\text { Duration } \\
\text { (weeks) }\end{array}$ & Most important outcomes \\
\hline \multirow[t]{2}{*}{ van Bunderen et al. (44) } & 2018 & 15 & IGF-1 -2 to -1 SDS & IGF-1 -1 to 1 SDS & 24 & More patient-reported fatigue \\
\hline & & 15 & IGF-1 1 to 2 SDS & & & $\begin{array}{l}\text { Decrease in waist circumference; decrease in } \\
\text { HDL-cholesterol (men); more patient-reported myalgia }\end{array}$ \\
\hline \multirow[t]{2}{*}{ van Bunderen et al. (43) } & 2016 & 15 & IGF-1 -2 to -1 SDS & IGF-1 -1 to 1 SDS & 24 & Less vigor \\
\hline & & 15 & IGF-1 1 to 2 SDS & & & Deterioration of working memory and strategic memory \\
\hline Drake et al. (18) & 1998 & 50 vs 21 & IGF-1 0 to 2 SDS & Weight-based regimen & 52 & $\begin{array}{c}\text { Rapid achievement of lower maintenance dose without } \\
\text { loss of efficacy (QoL, waist circumference), with no sex } \\
\text { difference }\end{array}$ \\
\hline $\begin{array}{l}\text { Johannsson } \\
\text { et al. (19) }\end{array}$ & 1997 & 30 vs 30 & $\begin{array}{l}\text { IGF-1 -2 to } 2 \text { SDS } \\
\text { + body composition }\end{array}$ & $\begin{array}{l}\text { Weight-based regimen } \\
\qquad(12 \mathrm{mg} / \mathrm{kg} / \text { day })\end{array}$ & 52 & $\begin{array}{c}\text { Fewer side effects; similar response to GHRT (body } \\
\text { composition, glucose homeostasis, lipoprotein(a), blood } \\
\text { pressure) }\end{array}$ \\
\hline
\end{tabular}

GHRT: growth hormone replacement therapy; HDL-cholesterol: high-density lipoprotein-cholesterol; IGF-1: insulin-like growth factor-1; QoL: quality of life; SDS: standard deviation score. 
efficacy in elderly hypopituitary patients with GHD, but at the same time these patients are more prone to develop side-effects to the treatment. At present there is no guidelines that recommend a chronological age when GHRT should be discontinued.

\section{SPECIAL SITUATIONS}

\section{Cardiovascular disease and diabetes mellitus}

Epidemiological studies show that hypopituitarism is associated with premature mortality due to cardiovascular and cerebrovascular disease. Beneficial effects of GHRT on cardiovascular risk factors are maintained for at least 10 years after initiation of therapy, with similar benefits seen in men and women when the GH dose is titrated to achieve a serum IGF-1 level between the median and the upper end of the age-related reference range (48). One theory as to why GHRT is beneficial with respect to cardiovascular disease is that a high-normal IGF-l target level demonstrates a reduction of waist circumference, which contributes to improvement of vascular function through regulation of sympathetic nervous system activity in the microcirculation in a recent unpublished trial (unpublished data, $\mathrm{C} \mathrm{v}$ Bunderen). However, the increased IGF-l level with higher doses of GH has also demonstrated a negative impact on insulin resistance, which will deteriorate microcirculation (49). Data on the effect of GHRT in adults with GHD on glucose metabolism remains a matter of debate. The two registry studies in the field have shown an initially increased risk of diabetes mellitus during GHRT in one of the studies and no increased risk in the other $(50,51)$. Epidemiological data on GHRT in non-functioning pituitary adenoma patients reported a normal incidence of type 2 diabetes mellitus (14). GH has an anti-insulin effect, but on the other hand, GHRT reduces abdominal fat mass and might therefore have a more beneficial effect on insulin resistance with longterm treatment (52). The increased insulin resistance obtained when increasing IGF-1 target level is likely to be due to a direct effect of increasing GH dose, with consequently increased lipolysis (53). Studies with very low GH dose $(0.1 \mathrm{mg} /$ day $)$ demonstrated improved insulin sensitivity without affecting body composition (54). The authors of this paper postulated that this effect is mediated by the ability to increase IGF-1 bioavailability in the absence of the unfavorable lipolytic effects seen with higher doses of $\mathrm{GH}$.

\section{Underlying diagnosis}

\section{Acromegaly}

Patients with GHD after previous acromegaly have an unfavorable metabolic profile which is comparable to that of patients with GHD after a non-functioning pituitary adenoma (55). GHRT in patients with previous acromegaly has been shown to improve metabolic parameters (56). However, contradictory results have also been published (57) and long-term data are sparse. The Dutch National Registry of long-term GHRT in adults demonstrated improvement of lipid profile in patients with previous acromegaly (58). However, glycated hemoglobin levels increased more compared to patients with non-functioning pituitary adenoma. GHRT in patients with GHD previously treated for acromegaly had no deleterious effect on cardiovascular morbidity. GHRT should not be withheld from patients with previous acromegaly, but close monitoring of glucose metabolism should be performed.

\section{Cushing's disease}

Patients with previous hypercortisolism show more long-term consequences of their disease, such as diabetes mellitus, hypertension, and fractures, compared to other etiologies of GHD (59). In multiple studies, patients with Cushing's disease and patients with other etiologies responded similarly to GHRT, suggesting that patients with GHD due to Cushing's disease benefit to the same extent as others $(60,61)$.

\section{Pituitary tumor or malignancy}

A study has raised some concern on the development of malignancies in children who received GHRT (62), but other studies are contradictory (63). A recent study on life expectancy in adults with pituitary adenoma receiving GHRT reported reduced overall mortality and a normal death rate due to cancer (13). Findings have also shown no association between cancer and serum IGF-1 level in adults with GHRT (64). Therefore, GHRT appears to be safe in GHD patients with respect to incidence and mortality due to malignancies $(65,66)$. Patients with a craniopharyngioma have a marked excess all-cause mortality (67) and GHRT does not seem to resolve this increased mortality risk $(65,68)$. GHRT together with other efforts related to the treatment of the underlying disorder and other pituitary hormone deficiencies should be further optimized in this patient 
population. Finally, long-term GHRT appears to be safe with regard to recurrence and enlargement of the primary pituitary tumor $(69,70)$.

\section{Pregnancy}

GHRT is not approved for use during conception and pregnancy. However, patients with hypopituitarism often conceive using assisted reproductive techniques and some studies support the benefit of GHRT in achieving fertility for women with GHD (71). The Pfizer International Metabolic Database (KIMS) analyzed pregnancies with different GHRT regimens, including stopping GHRT before pregnancy, as soon as pregnancy was confirmed, at the end of the second trimester, or continued throughout pregnancy. There was no relationship between the specific regimens and pregnancy outcome (72). Smaller studies have also demonstrated no negative influences of GHRT on maternal or fetal outcome (73). Physiologically, during gestation, the $\mathrm{GH}$ system is regulated by placental GH, which increases with the growth of the placenta and stimulates the maternal IGF1 level, leading to a concomitant decline in the pituitary GH level (74). There is no consensus on how to manage GHRT during pregnancy, but no harm has been shown with either stopping GHRT before pregnancy, adjusting the dose, or continuing throughout the pregnancy.

\section{CONCLUSION}

An individualized dose regimen with titration based on serum IGF-1 and clinical response should be used instead of weight- or body surface-based regimens to reduce side effects and to obtain similar efficacy. Women are less responsive to $\mathrm{GH}$, i.e. the same $\mathrm{GH}$ dose results in a lower serum IGF-1 level and a lesser effect on body composition compared to men. This difference between the sexes is especially seen in women taking oral estrogens. In order to obtain similar efficacy in men and women, women will therefore need a longer dose titration period and a higher daily GH dose than men. In addition, age at GHD onset affects the responsiveness of GHRT in adults, e.g. adults with childhood onset of GHD seem to have a more marked initial response to GHRT in terms of changes in body composition even though the long-term effects seem to be similar. A patient's genotype, including GH receptor isoforms, seems to have a weak effect on the responsiveness to GHRT and is, therefore, of little clinical significance. Even though not well investigated, adherence is most likely an important factor for responsiveness. Although the evidence is weak, it is suggested that individual GH dose is titrated on clinical response and towards a target serum IGF-1 level of 0 to 1 SDS without side effects.

Finally, the former excess mortality found in adult patients with hypopituitarism including GHD seems to approach normal with modern endocrine replacement therapy including GHRT. Furthermore, long-term GHRT appears to be safe regarding the incidence and mortality of malignancies, and the progression of the primary pituitary tumor. Many factors influence the response to GHRT, underlining the need for a personalized approach when treating patients with GHD.

Acknowledgement: the authors acknowledge Peter Todd (Tajut Ltd., Kaiapoi, New Zealand) for third-party writing assistance in drafting of this manuscript, for which he received financial compensation from ALF-funding.

Disclosure: DSO has been a consultant for Sandoz, Ipsen, and Pfizer, and received research grants from Sandoz; GJ has received lecture fees from Novartis, Novo Nordisk, Pfizer, Sandoz, Merck Serono, and Otsuka, and consultancy fees from Astra Zeneca and Shire; and CCvB and CG report no conflicts of interest.

\section{REFERENCES}

1. Frasier SD. The not-so-good old days: working with pituitary growth hormone in North America, 1956 to 1985. J Pediatr. 1997;131(1 Pt 2):S1-4.

2. Raben MS. Growth hormone. 2. Clinical use of human growth hormone. N Engl J Med. 1962;266:82-6.

3. FalkhedenT. Pathophysiological studies following hypophysectomy in man [Doctoral thesis]: University of Gothenburg; 1963.

4. Melmed S. Pathogenesis and diagnosis of growth hormone deficiency in adults. N Engl J Med. 2019;380(26):2551-62.

5. Kargi AY, Merriam GR. Diagnosis and treatment of growth hormone deficiency in adults. Nat Rev Endocrinol. 2013;9(6):335-45.

6. RosénT, Bengtsson BA. Premature mortality due to cardiovascular disease in hypopituitarism. Lancet. 1990;336(8710):285-8.

7. Stochholm K, Johannsson G. Reviewing the safety of $\mathrm{GH}$ replacement therapy in adults. Growth Horm IGF Res. 2015;25(4):149-57.

8. Salomon F, Cuneo RC, Hesp R, Sönksen PH. The effects of treatment with recombinant human growth hormone on body composition and metabolism in adults with growth hormone deficiency. N Engl J Med. 1989;321(26):1797-803.

9. Jørgensen JO, Pedersen SA, Thuesen $\mathrm{L}$, Jørgensen J, Ingemann-Hansen T, Skakkebaek NE, et al. Beneficial effects of growth hormone treatment in $\mathrm{GH}$-deficient adults. Lancet. 1989;1(8649):1221-5.

10. Maison P, Griffin S, Nicoue-Beglah M, Haddad N, Balkau B, Chanson P. Impact of growth hormone $(\mathrm{GH})$ treatment on cardiovascular risk factors in $\mathrm{GH}$-deficient adults: a metaanalysis 
of blinded, randomized, placebo-controlled trials. J Clin Endocrinol Metab. 2004;89(5):2192-9.

11. Appelman-Dijkstra NM, Claessen KM, Roelfsema F, Pereira AM, Biermasz NR. Long-term effects of recombinant human $\mathrm{GH}$ replacement in adults with GH deficiency: a systematic review. Eur J Endocrinol. 2013;169(1):R1-14.

12. Elbornsson M, Gotherstrom G, Bosaeus I, Bengtsson BA, Johannsson G, Svensson J. Fifteen years of GH replacement increases bone mineral density in hypopituitary patients with adult-onset GH deficiency. Eur J Endocrinol. 2012;166(5):787-95.

13. Olsson DS, Trimpou P, Hallén T, Bryngelsson IL, Andersson E, Skoglund $T$, et al. Life expectancy in patients with pituitary adenoma receiving growth hormone replacement. Eur J Endocrinol. 2017;176(1):67-75.

14. Hammarstrand $C$, Ragnarsson $O$, Bengtsson O, Bryngelsson IL, Johannsson G, Olsson DS. Comorbidities in patients with nonfunctioning pituitary adenoma: influence of long-term growth hormone replacement. Eur J Endocrinol. 2018;179(4):229-37.

15. Bengtsson BA, Edén S, Lonn L, Kvist $H$, Stokland A, Lindstedt G, et al. Treatment of adults with growth hormone $(\mathrm{GH})$ deficiency with recombinant human GH. J Clin Endocrinol Metab. 1993;76(2):309-17.

16. Holmes SJ, Shalet SM. Which adults develop side-effects of growth hormone replacement? Clin Endocrinol (Oxf). 1995;43(2):143-9.

17. Johannsson G, Bjarnason R, Bramnert M, Carlsson LM, Degerblad $M$, Manhem $P$, et al. The individual responsiveness to growth hormone $(\mathrm{GH})$ treatment in $\mathrm{GH}$-deficient adults is dependent on the level of $\mathrm{GH}$-binding protein, body mass index, age, and gender. J Clin Endocrinol Metab. 1996;81(4):1575-81.

18. Drake WM, Coyte D, Camacho-Hubner C, Jivanji NM, Kaltsas G, Wood DF, et al. Optimizing growth hormone replacement therapy by dose titration in hypopituitary adults. J Clin Endocrinol Metab. 1998;83(11):3913-9.

19. Johannsson G, Rosén $T$, Bengtsson BA. Individualized dose titration of growth hormone $(\mathrm{GH})$ during $\mathrm{GH}$ replacement in hypopituitary adults. Clin Endocrinol (Oxf). 1997;47(5):571-81.

20. Ho KK; 2007 GH Deficiency Consensus Workshop Participants. Consensus guidelines for the diagnosis and treatment of adults with GH deficiency II: a statement of the GH Research Society in association with the European Society for Pediatric Endocrinology, Lawson Wilkins Society, European Society of Endocrinology, Japan Endocrine Society, and Endocrine Society of Australia. Eur J Endocrinol. 2007;157(6):695-700.

21. Molitch ME, Clemmons DR, Malozowski S, Merriam GR, Vance $M L ;$ Endocrine Society. Evaluation and treatment of adult growth hormone deficiency: an Endocrine Society clinical practice guideline. J Clin Endocrinol Metab. 2011;96(6):1587-609.

22. Burman $P$, Johansson AG, Siegbahn A, Vessby B, Karlsson FA. Growth hormone $(\mathrm{GH})$-deficient men are more responsive to GH replacement therapy than women. J Clin Endocrinol Metab. 1997;82(2):550-5.

23. Johannsson G. Management of adult growth hormone deficiency. Endocrinol Metab Clin North Am. 2007;36(1):203-20.

24. Johannsson G, Gibney J, Wolthers T, Leung KC, Ho KK. Independent and combined effects of testosterone and growth hormone on extracellular water in hypopituitary men. J Clin Endocrinol Metab. 2005;90(7):3989-94.

25. Wolthers T, Hoffman DM, Nugent AG, Duncan MW, Umpleby $M$, Ho KK. Oral estrogen antagonizes the metabolic actions of growth hormone in growth hormone-deficient women. Am J Physiol Endocrinol Metab. 2001;281(6):E1191-6.

26. Weissberger AJ, Ho KK, Lazarus L. Contrasting effects of oral and transdermal routes of estrogen replacement therapy on 24-hour growth hormone $(\mathrm{GH})$ secretion, insulin-like growth factor I, and
GH-binding protein in postmenopausal women. J Clin Endocrinol Metab. 1991;72(2):374-81.

27. Koranyi J, Svensson J, Gotherström G, Sunnerhagen KS, Bengtsson B, Johannsson G. Baseline characteristics and the effects of five years of $\mathrm{GH}$ replacement therapy in adults with GH deficiency of childhood or adulthood onset: a comparative, prospective study. J Clin Endocrinol Metab. 2001;86(10):4693-9.

28. Attanasio AF, Lamberts SW, Matranga AM, Birkett MA, Bates PC, Valk NK, et al. Adult growth hormone (GH)-deficient patients demonstrate heterogeneity between childhood onset and adult onset before and during human GH treatment. Adult Growth Hormone Deficiency Study Group. J Clin Endocrinol Metab. 1997;82(1):82-8.

29. Barbosa EJ, Koranyi J, Filipsson H, Bengtsson BA, Boguszewski $\mathrm{CL}$, Johannsson $\mathrm{G}$. Models to predict changes in serum IGF1 and body composition in response to $\mathrm{GH}$ replacement therapy in $\mathrm{GH}$ deficient adults. Eur J Endocrinol. 2010;162(5):869-78.

30. Monson JP, Abs R, Bengtsson BA, Bennmarker H, FeldtRasmussen U, Hernberg-Stâhl $E$, et al. Growth hormone deficiency and replacement in elderly hypopituitary adults. KIMS Study Group and the KIMS International Board. Pharmacia and Upjohn International Metabolic Database. Clin Endocrinol (Oxf). 2000;53(3):281-9.

31. Jorge AA, Marchisotti FG, Montenegro LR, Carvalho LR, Mendonca BB, Arnhold IJ. Growth hormone (GH) pharmacogenetics: influence of $\mathrm{GH}$ receptor exon 3 retention or deletion on firstyear growth response and final height in patients with severe $\mathrm{GH}$ deficiency. J Clin Endocrinol Metab. 2006;91(3):1076-80.

32. Boguszewski CL, Barbosa EJL, Svensson PA, Johannsson G, Glad CAM. Clinical and pharmacogenetic aspects of the growth hormone receptor polymorphism. Eur J Endocrinol. 2017; 177(6):R309-21.

33. Glad CA, Barbosa EJ, Filipsson Nyström H, Carlsson LM, Nilsson $\mathrm{S}$, Nilsson AG, et al. SNPs within the GH-signaling pathway are associated with the early IGF1 response to $\mathrm{GH}$ replacement therapy in GHD adults. Eur J Endocrinol. 2014;170(1):101-7.

34. Barbosa EJ, Glad CA, Nilsson AG, Filipsson Nyström $H$, Götherström G, Svensson PA, et al. Genotypes associated with lipid metabolism contribute to differences in serum lipid profile of GH-deficient adults before and after GH replacement therapy. Eur J Endocrinol. 2012;167(3):353-62.

35. Barbosa EJ, Glad CA, Nilsson AG, Bosaeus N, Nyström HF, Svensson PA, et al. Extracellular water and blood pressure in adults with growth hormone $(\mathrm{GH})$ deficiency: a genotypephenotype association study. PLoS One. 2014;9(8):e105754.

36. Acerini CL, Segal D, Criseno S, Takasawa K, Nedjatian N, Röhrich $\mathrm{S}$, et al. Shared decision-making in growth hormone therapyimplications for patient care. Front Endocrinol (Lausanne). 2018;9:688.

37. Auer MK, Stieg MR, Hoffmann J, Stalla GK. Is insulin-like growth factor-I a good marker for treatment adherence in growth hormone deficiency in adulthood? Clin Endocrinol (Oxf). 2016;84(6):862-9.

38. Rosenfeld RG, Bakker B. Compliance and persistence in pediatric and adult patients receiving growth hormone therapy. Endocr Pract. 2008;14(2):143-54.

39. Graham S, Weinman J, Auyeung V. Identifying potentially modifiable factors associated with treatment non-adherence in paediatric growth hormone deficiency: a systematic review. Horm Res Paediatr. 2018;90(4):221-7.

40. Johannsson G, Bidlingmaier M, Biller BMK, Boguszewski M, Casanueva FF, Chanson P, et al. Growth Hormone Research Society perspective on biomarkers of $\mathrm{GH}$ action in children and adults. Endocr Connect. 2018;7(3):R126-34.

41. Abrahamsen B, Nielsen TL, Hangaard J, Gregersen G, Vahl N, Korsholm L, et al. Dose-, IGF-I- and sex-dependent changes in lipid 
profile and body composition during $\mathrm{GH}$ replacement therapy in adult onset GH deficiency. Eur J Endocrinol. 2004;150(5):671-9.

42. Cenci MCP, Soares DV, Spina LDC, Brasil RRdLO, Lobo PM, Michmacher $E$, et al. Comparison of two dose regimens of growth hormone $(\mathrm{GH})$ with different target IGF-1 levels on glucose metabolism, lipid profile, cardiovascular function and anthropometric parameters in GH-deficient adults. Growth Horm IGF Res. 2012;22(3-4):116-21.

43. van Bunderen CC, Lips $\mathrm{P}$, Kramer MH, Drent ML. Comparison of low-normal and high-normal IGF-1 target levels during growth hormone replacement therapy: a randomized clinical trial in adult growth hormone deficiency. Eur J Intern Med. 2016;31:88-93.

44. van Bunderen CC, Deijen JB, Drent ML. Effect of low-normal and high-normal IGF-1 levels on memory and wellbeing during growth hormone replacement therapy: a randomized clinical trial in adult growth hormone deficiency. Health Qual Life Outcomes. 2018;16(1):135.

45. Burman P, Johansson AG, Siegbahn A, Vessby B, Karlsson FA. Growth hormone $(\mathrm{GH})$-deficient men are more responsive to GH replacement therapy than women. J Clin Endocrinol Metab. 1997;82(2):550-5.

46. Chanson P, Arnoux A, Mavromati M, Brailly-Tabard S, Massart C, Young $J$, et al. Reference values for IGF-I serum concentrations: comparison of six immunoassays. J Clin Endocrinol Metab. 2016;101(9):3450-8.

47. Kokshoorn NE, Biermasz NR, Roelfsema F, Smit JW, Pereira AM, Romijn JA. GH replacement therapy in elderly GH-deficient patients: a systematic review. Eur J Endocrinol. 2011;164(5):657-65.

48. Götherström G, Bengtsson BA, Bosaeus I, Johannsson G, Svensson J. A 10-year, prospective study of the metabolic effects of growth hormone replacement in adults. J Clin Endocrinol Metab. 2007;92(4):1442-5.

49. de Boer MP, Meijer RI, Newman J, Stehouwer CD, Eringa EC, Smulders YM, et al. Insulin-induced changes in microvascular vasomotion and capillary recruitment are associated in humans. Microcirculation. 2014;21(5):380-7.

50. Luger $A$, Mattsson AF, Koltowska-Häggström $M$, Thunander $M$, Góth M, Verhelst J, et al. Incidence of diabetes mellitus and evolution of glucose parameters in growth hormone-deficient subjects during growth hormone replacement therapy: a longterm observational study. Diabetes Care. 2012;35(1):57-62.

51. Attanasio AF, Jung $H$, Mo D, Chanson P, Bouillon R, Ho KK, et al. Prevalence and incidence of diabetes mellitus in adult patients on growth hormone replacement for growth hormone deficiency: a surveillance database analysis. J Clin Endocrinol Metab. 2011;96(7):2255-61.

52. Svensson J, Fowelin J, Landin K, Bengtsson BA, Johansson JO. Effects of seven years of GH-replacement therapy on insulin sensitivity in GH-deficient adults. J Clin Endocrinol Metab. 2002;87(5):2121-7.

53. Møller N, Jørgensen JOL. Effects of growth hormone on glucose, lipid, and protein metabolism in human subjects. Endocr Rev. 2009;30(2):152-77.

54. Yuen KCJ, Dunger DB. Therapeutic aspects of growth hormone and insulin-like growth factor-I treatment on visceral fat and insulin sensitivity in adults. Diabetes Obes Metab. 2007;9(1): 11-22.

55. Lin E, WexlerTL, Nachtigall L, Tritos N, Swearingen B, Hemphill L, et al. Effects of growth hormone deficiency on body composition and biomarkers of cardiovascular risk after definitive therapy for acromegaly. Clin Endocrinol (Oxf). 2012;77(3):430-8.

56. Miller KK, WexlerT, Fazeli P, Gunnell L, Graham GJ, Beauregard C, et al. Growth hormone deficiency after treatment of acromegaly: a randomized, placebo-controlled study of growth hormone replacement. J Clin Endocrinol Metab. 2010;95(2):567-77.
57. van der Klaauw AA, Bax JJ, Roelfsema F, Stokkel MPM, Bleeker $\mathrm{GB}$, Biermasz NR, et al. Limited effects of growth hormone replacement in patients with $\mathrm{GH}$ deficiency during long-term cure of acromegaly. Pituitary. 2009;12(4):339-46.

58. van Bunderen CC, van Varsseveld NC, Heymans MW, Franken AA, Koppeschaar HP, van der Lely AJ, et al. Effect of long-term GH replacement therapy on cardiovascular outcomes in GH-deficient patients previously treated for acromegaly: a sub-analysis from the Dutch National Registry of Growth Hormone Treatment in Adults. Eur J Endocrinol. 2014;171(6):717-26.

59. Feldt-Rasmussen $U$, Abs $R$, Bengtsson BA, Bennmarker $H$, Bramnert M, Hernberg-Stahl $E$, et al. Growth hormone deficiency and replacement in hypopituitary patients previously treated for acromegaly or Cushing's disease. Eur J Endocrinol. 2002;146(1):67-74.

60. Hoybye $C$, Ragnarsson $O$, Jönsson PJ, Koltowska-Häggström $M$, Trainer $P$, Feldt-Rasmussen $U$, et al. Clinical features of $G H$ deficiency and effects of 3 years of $\mathrm{GH}$ replacement in adults with controlled Cushing's disease. Eur J Endocrinol. 2010;162(4): 677-84.

61. Johannsson G, Sunnerhagen KS, Svensson J. Baseline characteristics and the effects of two years of growth hormone replacement therapy in adults with growth hormone deficiency previously treated for Cushing's disease. Clin Endocrinol. 2004;60(5):550-9.

62. Swerdlow AJ, Higgins CD, Adlard P, Preece MA. Risk of cancer in patients treated with human pituitary growth hormone in the UK, 1959-85: a cohort study. Lancet. 2002;360(9329):273-7.

63. Bell J, Parker KL, Swinford RD, Hoffman AR, Maneatis T, Lippe $B$. Long-term safety of recombinant human growth hormone in children. J Clin Endocrinol Metab. 2010;95(1):167-77.

64. Popovic V, Mattsson AF, Gaillard RC, Wilton P, KoltowskaHaggstrom M, Ranke MB. Serum insulin-like growth factor I (IGF-I), IGF-binding proteins 2 and 3 , and the risk for development of malignancies in adults with growth hormone $(\mathrm{GH})$ deficiency treated with GH: data from KIMS (Pfizer International Metabolic Database). J Clin Endocrinol Metab. 2010;95(9):4449-54.

65. van Bunderen CC, van Nieuwpoort IC, Arwert LI, Heymans MW, Franken AAM, Koppeschaar HPF, et al. Does growth hormone replacement therapy reduce mortality in adults with growth hormone deficiency? Data from the Dutch National Registry of Growth Hormone Treatment in adults. J Clin Endocrinol Metab. 2011;96(10):3151-9.

66. Boguszewski CL, Boguszewski MCDS. Growth Hormone's Links to Cancer. Endocr Rev. 2019 Apr 1;40(2):558-574.

67. Olsson DS, Andersson E, Bryngelsson IL, Nilsson AG, Johannsson G. Excess mortality and morbidity in patients with craniopharyngioma, especially in patients with childhood onset: a population-based study in sweden. J Clin Endocrinol Metab. 2015;100(2):467-74.

68. Yuen KCJ, Mattsson AF, Burman P, Erfurth EM, Camacho-Hubner C, Fox JL, et al. Relative risks of contributing factors to morbidity and mortality in adults with craniopharyngioma on growth hormone replacement. J Clin Endocrinol Metab. 2018;103(2):768-77.

69. Olsson DS, Buchfelder M, Schlaffer S, Bengtsson BA, Jakobsson $K E$, Johannsson $G$, et al. Comparing progression of nonfunctioning pituitary adenomas in hypopituitarism patients with and without long-term GH replacement therapy. Eur J Endocrinol. 2009;161(5):663-9.

70. Olsson DS, Buchfelder M, Wiendieck K, Kremenevskaja N, Bengtsson BA, Jakobsson KE, et al. Tumour recurrence and enlargement in patients with craniopharyngioma with and without $\mathrm{GH}$ replacement therapy during more than 10 years of follow-up. Eur J Endocrinol. 2012;166(6):1061-8. 
71. Giampietro A, Milardi D, Bianchi A, Fusco A, Cimino V, Valle D, et al. The effect of treatment with growth hormone on fertility outcome in eugonadal women with growth hormone deficiency: report of four cases and review of the literature. Fert Steril. 2009;91(3):930.e7-11.

72. Vila G, Akerblad AC, Mattsson AF, RiedI M, Webb SM, Hana V, et al. Pregnancy outcomes in women with growth hormone deficiency. Fert Steril. 2015;104(5):1210-7.e1.
73. Wiren L, Boguszewski CL, Johannsson G. Growth hormone (GH) replacement therapy in $\mathrm{GH}$-deficient women during pregnancy. Clin Endocrinol (Oxf). 2002;57(2):235-9.

74. Vila G, Luger A. Growth hormone deficiency and pregnancy: any role for substitution? Minerva Endocrinol. 2018;43(4):451-7. 